\title{
Avaliação de resposta patológica em câncer de mama após quimioterapia neoadjuvante: padronização de protocolo adaptado
}

\author{
Assessment of pathological response in breast cancer after neoadjuvant chemotherapy: standardization of \\ adapted protocol
}

Cynthia Aparecida Bueno Toledo Osório1; Marcos Araújo Chaves Júnior²; Fernando Augusto Soares ${ }^{3}$

\begin{abstract}
unitermos
resumo

Câncer de mama

O conceito de resposta patológica completa (PCR) é controverso. Estudos prévios utilizaram diferentes

Quimioterapia

neoadjuvante

Resposta patológica

Protocolo métodos de avaliação da pCR, porém não há um consenso universal sobre o melhor protocolo para o estudo das peças cirúrgicas de pacientes portadoras de carcinoma mamário submetidas ao tratamento quimioterápico neoadjuvante. Symmans et al. desenvolveram um sistema de classificação de carga residual de câncer (RCB) de mama após quimioterapia neoadjuvante, analisando a dimensão do leito tumoral primário, a porcentagem de células neoplásicas viáveis residuais no leito tumoral e o comprometimento linfonodal. Apresentamos uma proposta de avaliação da resposta patológica nos tumores de mama após quimioterapia neoadjuvante, por meio de um protocolo adaptado à nossa rotina de exame anatomopatológico de peças cirúrgicas, com base no estudo de Symmans et al.
\end{abstract}

\section{abstract}

The concept of pathologic complete response $(p C R)$ is controversial. Previous studies used different methods of $p C R$ assessment, but there is no universal consensus about the best protocol for the study of surgical specimens from patients with breast carcinoma undergoing neoadjuvant chemotherapy. Symmans et al. developed a classification system of residual cancer burden $(R C B)$ after neoadjuvant chemotherapy for breast cancer analyzing the extent of primary tumor bed, the percentage of residual viable tumor cells in the tumor bed and lymph node involvement. We present a proposal for the evaluation of pathological response in breast tumors after neoadjuvant chemotherapy. Based on Symmans et al. study, it consists in a protocol adapted to our routine pathological examination of surgical specimens. key words

Breast cancer

Neoadjuvant chemotherapy

Pathological response

Protocol

1. Mestra em Oncologia pela Fundação Antônio Prudente (FAP); patologista titular do Departamento de Anatomia Patológica do Hospital do Câncer A. C. Camargo.

2. Patologista titular do Departamento de Anatomia Patológica do Hospital do Câncer A.C. Camargo.

3. Livre-docente da Universidade de São Paulo (USP); diretor do Departamento de Anatomia Patológica do Hospital do Câncer A.C. Camargo. 


\section{Introdução}

O conceito de resposta patológica completa (pCR) é controverso. Vários protocolos anatomopatológicos para investigação de resposta patológica têm sido propostos na literatura ${ }^{(1,3-7,11-13)}$. O The National Surgical Adjuvant Breast and Bowel Project (NSABP-18) ${ }^{(5)}$ o definiu como ausência de câncer invasivo residual, embora permita a presença de carcinoma ductal in situ (CDIS) e linfonodos axilares positivos ${ }^{(5)}$. Além dos investigadores participantes do NSABP-18, outros, como Miller et al..$^{(5)}$ e Chevallier ${ }^{(3)}$, assumem como pCR a ausência de carcinoma invasivo $(\mathrm{Cl})$ residual, mas possibilitando a presença de CDIS, entretanto, Chevallier ${ }^{(3)}$ subdivide os casos de $\mathrm{pCR}$ como sem e com CDIS (classes 1 e 2 , respectivamente). Symmans et al. propõem uma definição mais restrita, incluindo, nesse conceito, apenas pacientes que não apresentam $\mathrm{Cl}$ residual (pT0), celularidade residual mínima, CDIS e metástase linfonodal ${ }^{(14)}$. A pCR é um bom marcador da eficácia do tratamento(6), contudo, diferentes sistemas têm sido propostos e não há métodos padronizados para graduar a resposta patológica nos tumores que receberam quimioterapia (QT) neoadjuvante ${ }^{(3,4,13)}$.

Miller et al., em 2003, apresentaram um sistema de avaliação histológica de resposta em câncer de mama após QT, com base apenas na celularidade, sem considerar o tamanho do tumor pré-QT e o status linfonodal após o tratamento neoadjuvante(11). Em 2005, Carey et al. demonstraram que pacientes que não apresentavam comprometimento linfonodal após o tratamento possuem excelente sobrevida ${ }^{(7)}$, assim, quanto menor o tamanho do tumor, menor a celularidade de câncer residual, o que determina o prognóstico(2). Com base nesse fato, Symmans et al. desenvolveram um sistema de classificação de carga residual de câncer (RCB) de mama após QT neoadjuvante, analisando a dimensão do leito tumoral primário, a porcentagem de células neoplásicas viáveis residuais no leito tumoral e o comprometimento linfonodal( ${ }^{(14)}$. O sistema de avaliação da resposta patológica após o tratamento quimioterápico neoadjuvante proposto por Symmans et al. apresenta algumas diferenças relevantes em relação aos sistemas propostos anteriormente, incluindo a observação microscópica de ausência do componente CDIS na avaliação da $\mathrm{pCR}$, critério não incluído em outros protocolos já mencionados ${ }^{(5,11)}$. Ademais, os critérios de Symmans et al. são mais restritos e pormenorizados, diminuindo as diferenças de interpretação e aumentando a reprodutibilidade de aplicação do método.

A comparação da dimensão do leito tumoral primário macroscópico com a dimensão microscópica residual tumoral em milímetros, associada à avaliação estimativa da porcentagem de celularidade viável em relação às áreas de resposta tumoral (proliferação de fibroblastos jovens, neoformação capilar, fibrose hialina e/ou processo inflamatório com hemossiderófagos), fornecem dados quantitativos e qualitativos, nunca associados anteriormente aos diferentes protocolos relatados na literatura. Assim também, a inclusão da avaliação do número de metástases linfonodais presentes e da dimensão da maior metástase em milímetros, não mencionadas em outros protocolos, são importantes fatores para correlação prognóstica, formando em conjunto o pilar dos critérios anatomopatológicos necessários para a associação objetiva dos resultados com sobrevida livre de recorrência, a partir de um índice matemático denominado RCB, obtido no site do MD Anderson ${ }^{(10)}$. O fácil acesso ao índice, mediante o preenchimento dos dados numéricos fornecidos pelo patologista diretamente no site, possibilita a interpretação prognóstica pela equipe multidisciplinar que atende a paciente.

Apresentamos a seguir, um protocolo de avaliação da resposta patológica nos tumores de mama após QT neoadjuvante, adaptado à nossa rotina de exame anatomopatológico de peças cirúrgicas, com base no que foi proposto por Symmans et al. O presente protocolo foi estabelecido ao longo de nossa experiência, por um período de dois anos (2010 a 2012), em mais de 150 peças cirúrgicas provenientes de pacientes com câncer de mama tratadas em nosso hospital, com cirurgia e QT neoadjuvante. Realizamos algumas adaptações à proposta original, fundamentadas na dimensão da neoplasia residual observada em nosso estudo. $\mathrm{O}$ artigo de Symmans et al. demonstrou que a representação macroscópica de toda a área de neoplasia residual, em muitos casos, pode ser observada microscopicamente, em poucas lâminas que contêm os cortes histológicos capazes de se encaixarem como se fossem um quebra-cabeças, devido à sua pequena dimensão. Já em nossa experiência, muitos tumores residuais apresentaram grandes dimensões, por vezes maiores do que $5 \mathrm{~cm}$. Preconizamos os cortes macroscópicos da peça cirúrgica sempre no sentido lateromedial. A fibrose constantemente presente no estroma mamário após o tratamento quimioterápico dificulta a precisa avaliação do eixo da maior dimensão tumoral residual (anteroposterior ou lateromedial), não sendo possível escolher o melhor sentido do corte macroscópico, seja pela radiografia ou pela palpação da peça cirúrgica, previamente ao corte. Realizamos cortes amostrais representativos e previamente designados de acordo com o mapeamento macroscópico das diversas áreas heterogêneas, observadas na fatia que 
contém a maior área do leito tumoral primário. Nos tumores de grandes dimensões, a amostragem de outras áreas da neoplasia residual nas fatias adjacentes à principal escolhida nos fornece informações para a avaliação microscópica de sua segunda maior dimensão, dado necessário para 0 adequado preenchimento do protocolo no site do MD Anderson. A representação apenas amostral de fragmentos de grandes tumores residuais é suficiente para a avaliação estimativa da dimensão (em milímetros) e da celularidade (em porcentagem) da neoplasia residual, fornecendo, assim, os parâmetros preconizados por Symmans et al. necessários para a avaliação do RCB. Além disso, examinamos áreas de todos os quadrantes, pele, mamilo e margens cirúrgicas (produtos de mastectomia ou cirurgias conservadoras), assim como os linfonodos do esvaziamento axilar, de acordo com os protocolos macroscópicos empregados em nossa rotina de patologia cirúrgica.

\section{Objetivos}

O presente protocolo de avaliação de resposta patológica em câncer de mama após QT neoadjuvante visa a fornecer dados microscópicos da dimensão do leito tumoral primário residual pós-tratamento, da porcentagem estimada média de celularidade tumoral global (carcinoma in situ $[\mathrm{ClS}]+\mathrm{Cl}$ ) e da porcentagem estimada média de celularidade tumoral apenas do componente in situ residual e a avaliar a metástase linfonodal para a obtenção de um índice de carga residual de câncer, que se relaciona com a quantidade de resposta patológica tumoral e com o prognóstico.

\section{Estudo macroscópico}

Considerações importantes:

- O posicionamento anatômico da peça cirúrgica deverá ser conhecido no momento do exame anatomopatológico (lateralidade em caso de produto de mastectomia e designação das margens cirúrgicas com fios; por exemplo, um fio, margem superior; dois fios, margem inferior; três fios, margem lateral; quatro fios, margem medial; e cinco fios, margem profunda em produtos de ressecção) (Figura 1).

- A localização e o tamanho do tumor primário (por palpação e/ou exame de imagens pré-tratamento) devem ser conhecidos no momento da avaliação.

- Recomenda-se a utilização de clip metálico para a demarcação do leito tumoral primário no momento

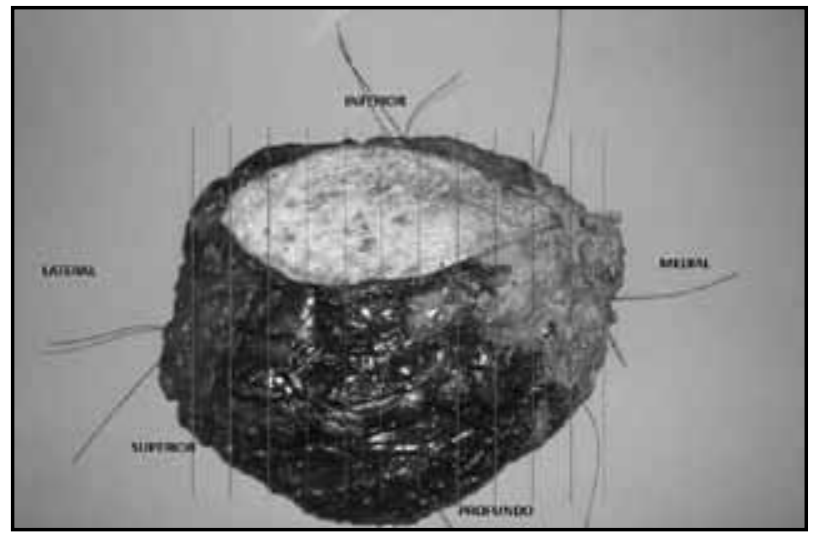

Figura 1 -Fotografia macroscópica de produto de ressecção segmentar da mama direita. As margens cirúrgicas foram previamente demarcadas com fios cirúrgicos e pintadas com tinta nanquim de cores diferenciadas, segundo o protocolo interno utilizado em nosso serviço

da biópsia diagnóstica e a realização de raio $X$ da peça cirúrgica para a avaliação da correta área de tumor primário pós-tratamento.

- Toda peça cirúrgica será submetida a fatias macroscópicas com $1 \mathrm{~cm}$ de espessura no sentido lateromedial.

- As fatias macroscópicas da peça cirúrgica serão analizadas sequencialmente para a obtenção daquela que contenha a maior área suspeita de neoplasia residual. Se o tumor estiver contido em mais de uma fatia, essa informação deverá ser computada para a estimativa final da dimensão do leito tumoral residual.

- A medida estimada do leito tumoral primário residual será obtida sempre com as suas duas maiores dimensões.

- Realizar fotocópia ou fotografia da(s) fatia(s) selecionada(s) (Figura 2).

- Fazer uma grade com $1 \times 1 \mathrm{~cm}$ ou $2 \times 2 \mathrm{~cm}$ na fotocópia para mapear o leito tumoral primário residual.

- Cortes histológicos representativos do leito tumoral primário residual, medindo em torno de $1 \times 1 \mathrm{~cm}$ ou $2 \times 2 \mathrm{~cm}$ deverão ser realizados para estimarem a dimensão final microscópica da neoplasia residual em milímetros. Tumores residuais pequenos poderão ser completamente representados; tumores residuais de grandes dimensões, com predomínio de neoplasia viável, poderão ser amostrados macroscopicamente (Figura 3).

- A área de transição do leito do tumor residual com o tecido preservado adjacente deve ser incluída na análise histológica. 


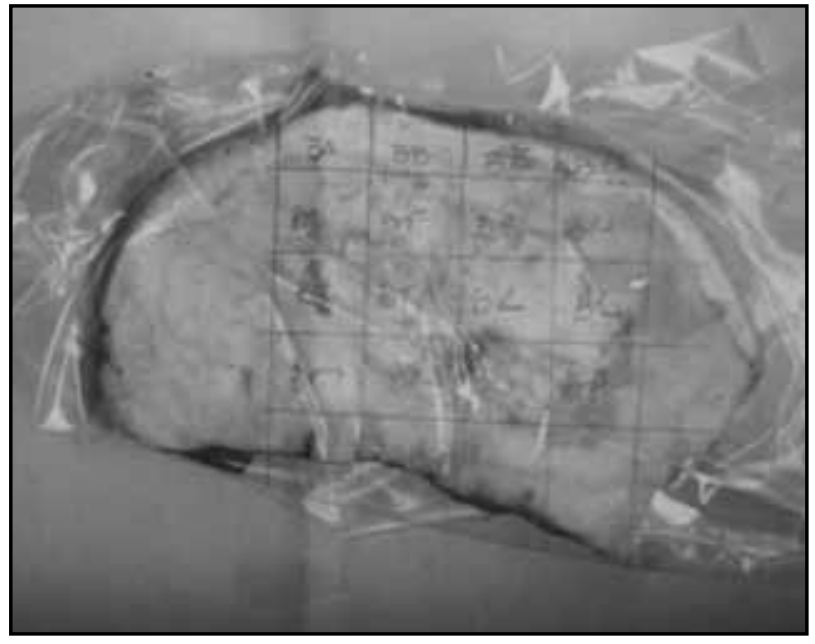

Figura 2 - Fotocópia da fatia macroscópica selecionada. A fatia selecionada é envolta em saco plástico transparente. Efetuamos uma fotocópia em máquina comum de xerox. Cada quadrículo receberá uma designação prévia, como visualizamos nesse exemplo (BA, $B B, B C$, etc.)

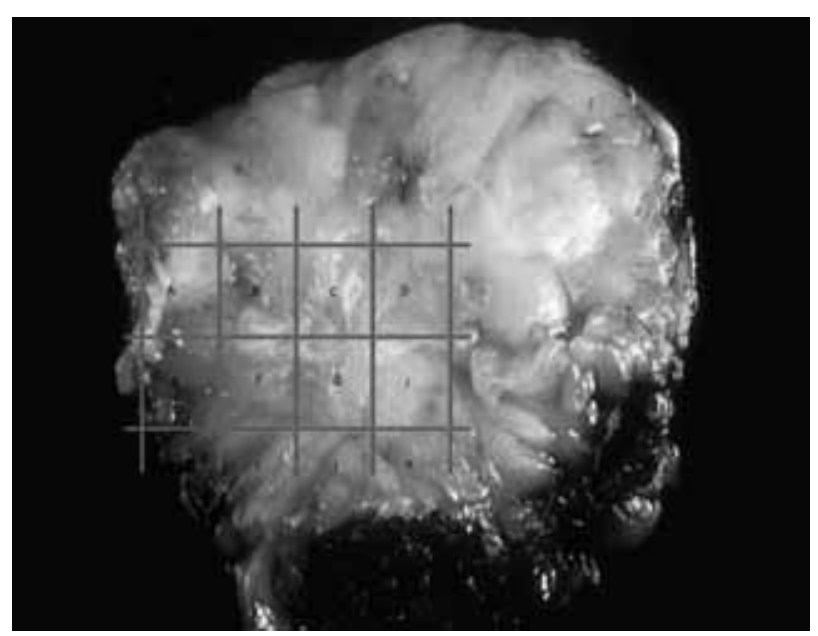

Figura 3 - Outro exemplo de fatia macroscópica de peça cirúrgica contendo a maior área de leito tumoral residual. A grade para representação de toda a área mapeada está representada e os quadrículos designados como $A, B, C$ etc. Cada quadrículo demarcado corresponderá a uma lâmina de histologia

- Cada lâmina de hematoxilina e eosina (HE) deverá conter uma secção de tecido previamente designada ( $A A, A B, A C$...) a partir do mapeamento macroscópico.

- Em caso de doença multicêntrica, as dimensões utilizadas para o cálculo final deverão ser as correspondentes ao maior foco de tumor residual.

- - Outras áreas macroscopicamente suspeitas, lesões ou achados macroscópicos, assim como todas as amostragens dos protocolos macroscópicos de rotina de peça cirúrgica mamária, como pele, mamilo, parênquima de todos os quadrantes, margens cirúrgicas e linfonodos, deverão ser incluídos na representação macroscópica.

\section{Avaliação microscópica}

Recomenda-se delimitar a área do tumor residual nas lâminas de histologia com pontos de tinta para facilitar a estimativa da dimensão residual (Figura 4).

O patologista precisa ter fácil acesso aos diagramas de porcentagem da celularidade da neoplasia viável residual em cada lâmina histológica examinada, e estes foram fornecidos por Symmans et al. no artigo original, e funcionarão como um guia para estimar com maior precisão a celularidade tumoral (Figuras 5, 6A e 6B). Segue o link com a ilustração gráfica de percentual celularidade do câncer: http://mdanderson.org/breastcancer_RCB ${ }^{(10)}$.

É necessário estimar a celularidade da neoplasia residual em cada lâmina de histologia com os seguintes parâmetros: celularidade global de câncer residual $(\% \mathrm{CA})=\% \mathrm{ClS}+\% \mathrm{Cl}$, e a porcentagem de doença in situ apenas (\%CIS).

As duas maiores dimensões macroscópicas do leito do tumor residual deverão ser corrigidas após a sua avaliação microscópica para a estimativa microscópica final (em milímetros). Ou seja, a medida microscópica final é a que será utilizada para o preenchimento do protocolo e para a obtenção do índice de RCB. A estimativa é utilizada supostamente para representar a média em toda a área do leito tumoral residual. Deve ser notado que a dimensão final microscópica poderá ser maior, igual ou menor do que a dimensão previamente estimada no exame macroscópico do leito tumoral residual (Figura 7).

Na ausência de neoplasia residual após a amostragem da área do leito tumoral primário, o patologista deve incluir cortes adicionais de tecido da peça cirúrgica para nova avaliação microscópica e confirmação de pCR.

\section{Exame dos linfonodos regionais}

a) Contar o número de linfonodos (LN) positivos ao exame microscópico. b) Medir o maior diâmetro da maior metástase linfonodal (dmet) (Figura 8).

\section{Metástases em linfonodos mamários internos}

As metástases mamárias internas linfonodais não foram incluídas no estudo de Symmans et al. para avaliar o valor prognóstico do índice do RCB. No entanto, quando presentes, recomenda-se incluí-las no cálculo do índice de RCB. 


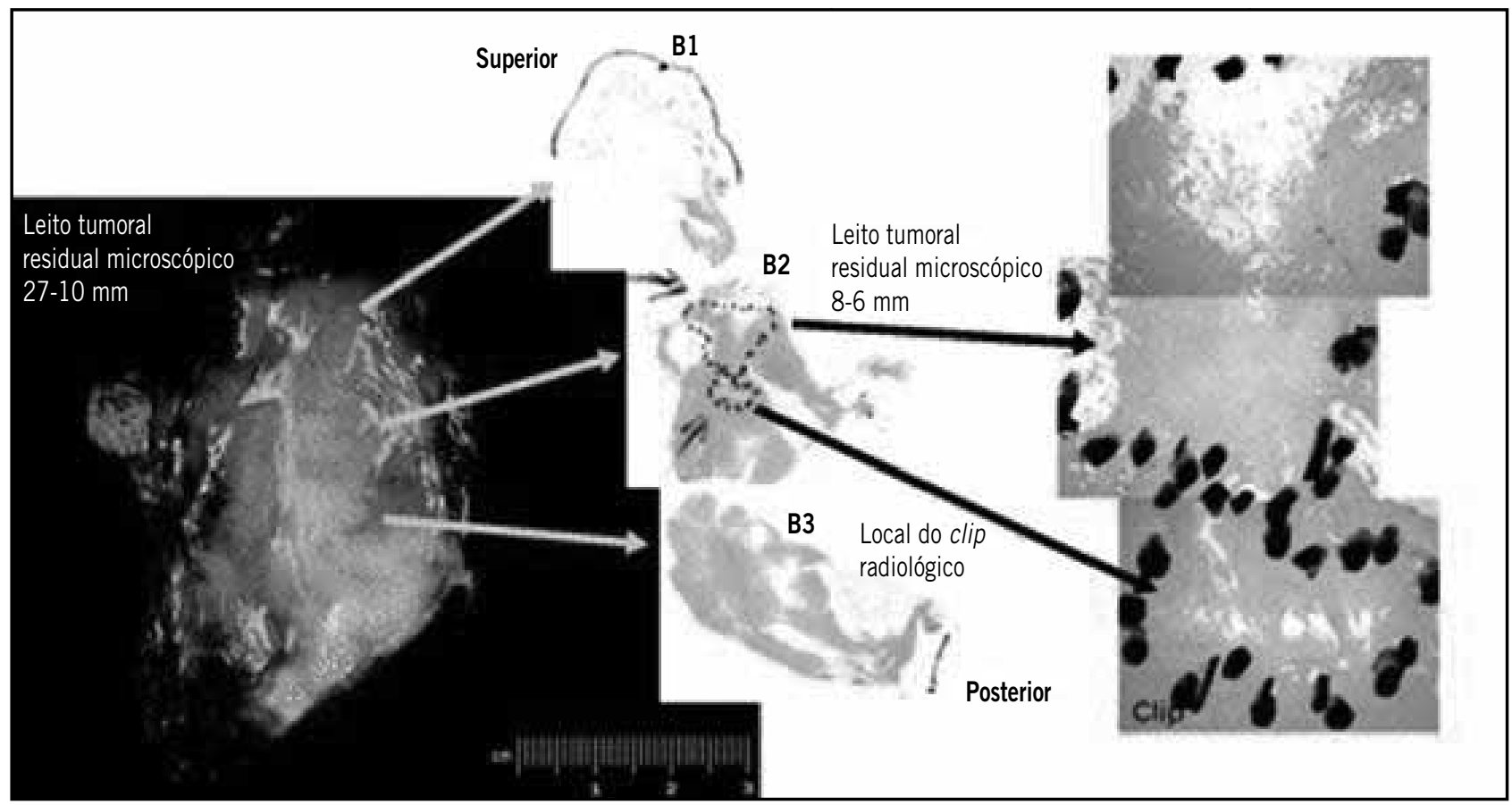

Figura 4 - Delimitação da área microscópica do tumor residual nas lâminas de histologia com pontos de tinta para a estimativa da dimensão residual. Retirado de Symmans et al.(14) B1: bloco de parafina 1; B2: bloco de parafina 2; B3: bloco de parafina 3.

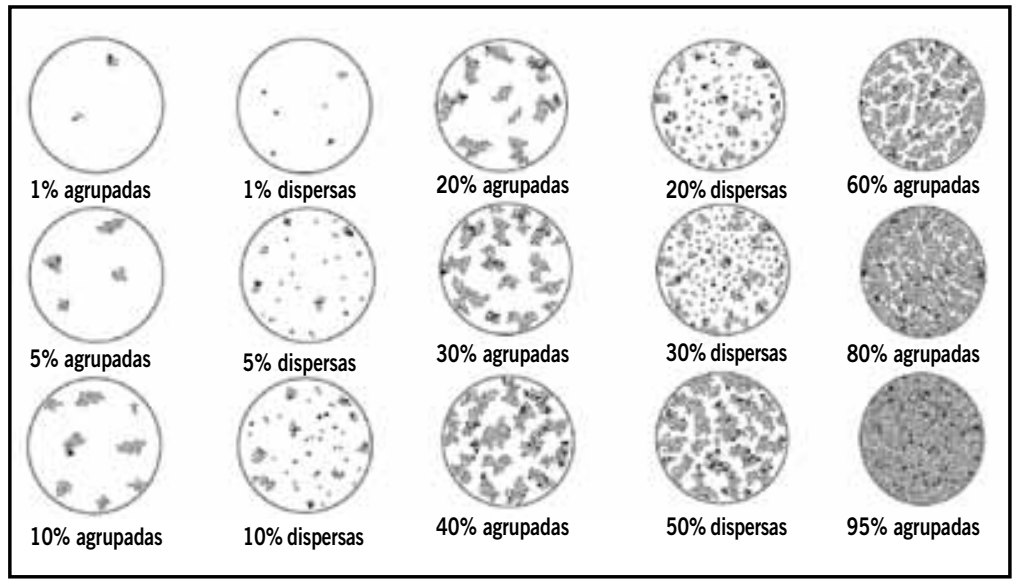

Figura 5 - Diagrama de porcentagem da celularidade da neoplasia viável residual Fonte: Guide for Measuring Cancer Cellularity. Symmans et al. (2007)(14).

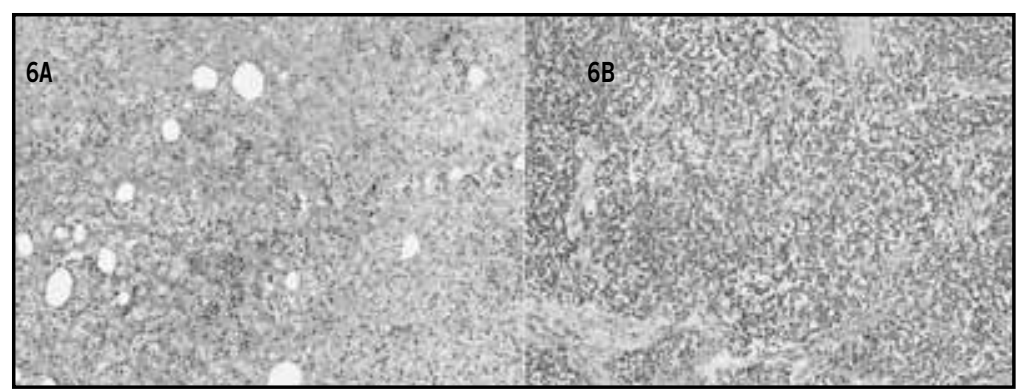

Figura 6 - Áreas de resposta completa e câncer residual

6A: fotografia microscópica da área de resposta patológica completa, representada por fibrose e agregados de histiócitos xantomatosos. Ausência de neoplasia viável residual. HE, 10x; 6B: fotografia microscópica de carcinoma mamário invasivo residual. Presença de $80 \%$ de celularidade neoplásica viável pós-quimioterapia prévia. $H E, 10 x$.

$H E$ : hematoxilina e eosina.

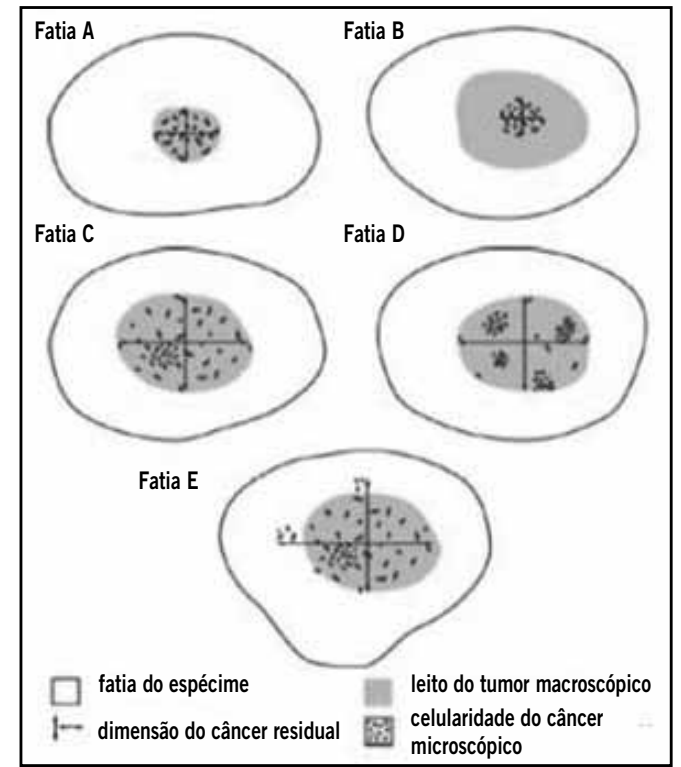

Figura 7 - Esquema demonstrando que a dimensão final microscópica poderá ser maior, igual ou menor do que a dimensão previamente estimada no exame macroscópico do leito tumoral residual Fonte: Symmans et al. (2007)(14). 


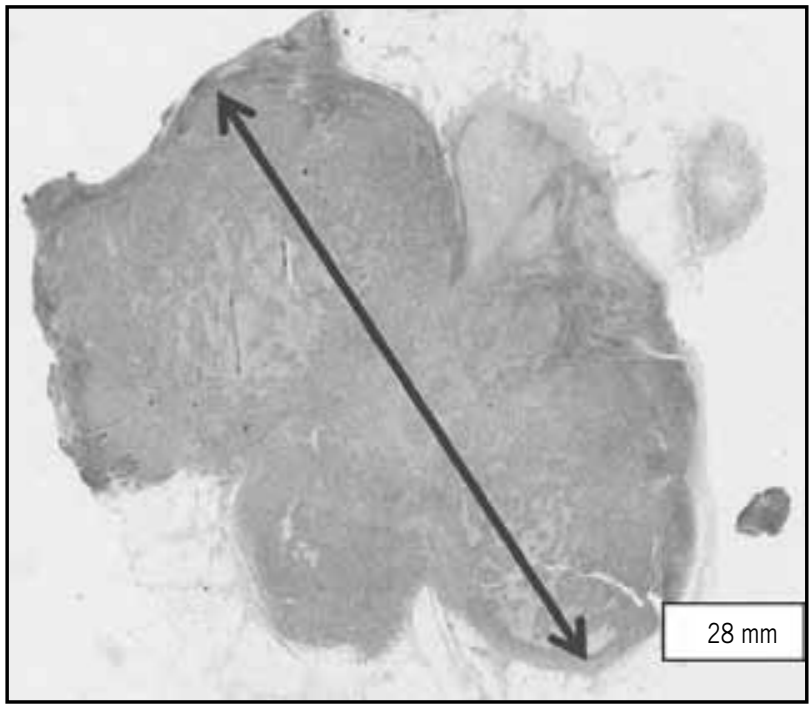

Figura 8 - Fotografia microscópica de corte longitudinal de linfonodo axilar com macrometástase de carcinoma medindo $28 \mathrm{~mm}$ na maior dimensão, sem extravazamento capsular

antes do tratamento neoadjuvante invalida a precisão da avaliação do RCB. Porém, se todos os linfonodos sentinela forem negativos antes do tratamento quimioterápico, a sua inclusão no cálculo não afetará a avaliação do RCB após o tratamento.

\section{Comentários importantes}

- A exclusiva embolização linfática do tumor deve ser interpretada como tumor residual na mama após o tratamento.

- O extravasamento capsular deve ser incluído na dimensão da metástase microscópica linfonodal. A embolização linfática do tumor no parênquima do linfonodo deve ser interpretada como câncer residual.

- A embolização linfática mínima do tumor fora da cápsula do linfonodo não deve ser interpretada como câncer residual.

\section{Cálculo do índice de RCB}

Cinco variáveis microscópicas estão incluídas no cálculo final do índice de RCB: medida do leito tumoral residual microscópico em milímetros (primary tumor bed area); porcentagem da celularidade de câncer residual global (overall cancer cellularity); porcentagem da celularidade apenas do componente in situ (cancer that is in situ disease); número de linfonodos positivos; e diâmetro da maior metástase em milímetros. Com esses resultados obtidos, o médico pode acessar o link http://mdanderson.org/breastcancer_RCB(10).
O preenchimento desses dados fornecerá um resultado automático de um de índice de RCB e a informação da classe de RCB correspondente ( $\mathrm{PCR}$, doença residual mínima [RCB-1], doença residual moderada [RCB-II] e doença residual extensa [RCB-III]). As classes de RCB relacionam-se diretamente com o prognóstico e a sobrevida livre de doença.

\section{Resumo}

- O índice de RCB de câncer residual pós-QT neoadjuvante acrescenta informação prognóstica;

- consegue fornecer informação prognóstica diferenciada entre a $\mathrm{pCR}$ e a doença residual mínima (RD);

- combina a dimensão patológica do leito do tumor primário, a celularidade tumoral residual e a metástase linfonodal (número e tamanho) para prever sobrevida livre de doença;

- quatro parâmetros de tumor residual (dimensão do leito tumoral residual [Dprime], porcentagem do $\mathrm{Cl}$, LN comprometidos e dmet) são individualmente associados ao risco significativamente maior de recorrência a distância;

- o método pode ser facilmente incorporado na prática de diagnóstico: o patologista fornece as variáveis usadas para calcular o RCB e junto com o oncologista e o cirurgião podem fazer o cálculo automático no site MD Anderson ${ }^{(10)}$.

\section{Justificativas para a utilização do protocolo}

O sistema proposto por Symmans et al., como já mencionamos na introdução deste artigo, oferece informações anatomopatológicas adicionais aos protocolos anteriormente descritos. Ele compara as dimensões pré e pós-tratamento, levando em conta a presença de células viáveis neoplásicas distribuídas em toda a extensão do leito tumoral primário. Essa avaliação permite menor subestimação da dimensão da área de tumor residual, aliada à possibilidade de quantificar a celularidade viável estimada em porcentagem, em muitos casos, distribuída de forma muito irregular e esparsa, em meio a áreas de resposta patológica tumoral.

É frequente observarmos em uma extensa área de fibrose hialina compatível com resposta patológica focos microscópicos de neoplasia residual, distantes entre si, contidos na região da periferia do leito tumoral primário. 
Ou seja, embora a dimensão tumoral possa permanecer igual à avaliação pré-tratamento, a celularidade pode ser reduzida substancialmente ${ }^{(12)}$.

O protocolo de Symmans et al. também proporciona correlação com sobrevida livre de recorrência a distância por meio da obtenção do cálculo do índice de RCB. Além disso, o material analisado e seus resultados poderão gerar subsídios básicos para novos estudos em pesquisa científica. Vários artigos publicados na literatura, posteriores aos de Symmans et al., em 2007, têm citado esse estudo como um indicador preciso da medida da carga de neoplasia residual e sugere o emprego desse protocolo para adequada avaliação da resposta patológica ${ }^{(8,9,12)}$. Outros autores sugerem que sejam comparados os diversos sistemas de avaliação de resposta patológica para a escolha do que será mais eficaz para estudos populacionais de sobrevida ${ }^{(15)}$.
Protocolo anatomopatológico final proposto Informações anatomopatológicas relevantes

- Dimensão do leito tumoral primário macroscópico: milímetros.

- Dimensão do leito tumoral residual microscópico: milímetros.

- Neoplasia residual microscópica: presente ( ) ausente ( ).

- Porcentagem de celularidade do carcinoma global residual: \%

- Porcentagem de celularidade do carcinoma residual in situ: \%

- LN positivos:

- dmet: milímetros.

Após calcular o índice de RCB usando a página on-line, o médico obterá as seguintes informações: carga de câncer residual (índice de RCB) e classe de RCB (pCR, RCB-I, RCB-II e RCB-III).

\section{Referências}

1. BARBOSA, E. M. et al. Tumor residual pós-quimioterapia neoadjuvante para câncer de mama: impacto sobre o tratamento cirúrgico conservador/residual tumor after neoadjuvant chemotherapy for breast cancer: impact on conservative surgical treatment. Rev Bras Ginecol Obstet, v. 21, n. 4, p. 187-92, 1999.

2. CAREY, L. A. et al. American Joint Committee on Cancer tumor-node-metastasis stage after neoadjuvant chemotherapy and breast cancer outcome. J Natl Cancer Inst, v. 97, n. 15, p. 1137-42, 2005.

3. CHEVALLIER, B. et al. Inflammatory breast cancer: pilot study of intensive induction chemotherapy (FEC-HD) results in a high histologic response rate. J Clin Oncol, v. 16, p. 223-8, 1993.

4. FISHER, B. et al. Effect of preoperative chemotherapy on the outcome of women with operable breast cancer. J Clin Oncol, v. 16, p. 2672-85, 1998.

5. FISHER, E. R. et al. Pathobiology of preoperative chemotherapy. Findings from the National Surgical Adjuvant Breast and Bowel Project (NSABP). Protocol B-Cancer, v. 95, n. 4, p. 681-95, 2002.

6. GUARNERI, V. et al. Prognostic value of pathologic complete response after primary chemotherapy in relation to hormone receptor status and other factors. J Clin Oncol, v. 24, n. 7, p. 1037-44, 2006.

7. HENNESSY, B. T. et al. Outcome after pathologic complete eradication of cytologically proven breast cancer axillary node metastases following primary chemotherapy. J Clin Oncol, v. 20, n. 36, p. 9304-11, 2005.

8. JERUSS, J. S. et al. Staging of breast cancer in the neoadjuvant setting. Cancer Res, v. 68, n. 16, 2008.
9. KAUFMANN, M. et al. Recommendations from an international consensus conference on the current status and future of neoadjuvant systemic therapy in primary breast cancer. Ann Surg Oncol, v. 19, p. 1508-16, 2012.

10. MD Anderson Cancer Center. Residual Cancer Burden Calculator. Disponível em: <http://mdanderson.org/ breastcancer_RCB>. Acesso em: maio 2012.

11. OGSTON, K. N. et al. A new histological grading system to assess response of breast cancers to primary chemotherapy: prognostic significance and survival. Breast, v. 12, p. 320-7, 2003.

12. SAHOO, S.; LESTER, S. C. Pathology of breast carcinomas after neoadjuvant chemotherapy an overview with recommendations on specimen processing and reporting. Arch Pathol Lab Med, v. 133, 2009.

13. SATALOFF, D. M. et al. Pathologic response to induction chemotherapy in locally advanced carcinoma of the breast: a determinant of outcome. J Am Coll Surg, v. 180, p. 297-304, 1995.

14. SYMANNS, W. F. etal. Measurement of residual breast cancer burden to predict survival after neoadjuvant chemotherapy. J Clin Oncol, v. 25, n. 28, p. 4414-22, 2007.

15. VON MINCKWITZ, G. et al. Definition and impact of pathologic complete response on prognosis after neoadjuvant chemotherapy in various intrinsic breast cancer subtypes. JCO, v. 30, n. 15, p. 1796-1804, 2012.

Endereço para correspondência

Hospital do Câncer A. C. Camargo Departamento de Anatomia Patológica Rua Professor Antônio Prudente, 211 Liberdade

CEP: 01509-010 - São Paulo-SP 